\title{
AS RELAÇÕES DE APROPRIAÇÃO DO PASSA- DO CELTA E DA FIGURA DE BOADICEA
}

\section{THE RELATIONS OF APPROPRIATION OF THE CELTIC PAST OF THE FIGURE OF BOADICEA}

Pricyla Weber $^{1}$, Thaís Cattani Perroni. $^{2}$

Resumo: O presente trabalho tem por objetivo analisar o como a religião celta foi ressignificada ao longo dos séculos e as motivações disso a partir da ferramenta crítica dos usos do passado. Por meio da análise da bibliografia sobre a trajetória da religião celta e sobre a figura de Boudicea, apresentamos uma análise crítica sobre a romantização dos elementos célticos e sobre a utilização do passado para legitimação política no presente.

Palavras-chave: Celtas; Druidas; Religião; Usos do Passado.

Abstract: The present work aims to analyze the main arguments, guidelines and questions about the discussions about the uses of the Roman past in the region of England and on the Celtic religion. Through the analysis of the literature on the trajectory of Celtic religion and the figure of Boudicea, we present a critical analysis on the romanticization of the Celtic elements and on the use of the past for political legitimation in the present.

Keywords: Celts; Druids; Religion; Uses of the Past.

\section{Introdução}

${ }^{1}$ Graduanda de História Memória e Imagem, pela Universidade Federal do Paraná. Possui experiência na área de história, com ênfase em história contemporânea e Oriente médio.

${ }^{2}$ Graduanda do Curso História Bacharel e Licenciatura, pela Universidade Federal do Paraná. Bolsista do PET história UFPR. Possui experiência em história. 
O presente artigo é uma versão ampliada do trabalho de conclusão da disciplina Tópicos Especiais de Historiografia sobre a Antiguidade. A proposta da disciplina era repensar os aspectos do mundo romano imperial a partir da reflexão sobre a chegada dos romanos à Britannia. Desse modo, o artigo apresentado tem por finalidade analisar o como a religião celta foi ressignificada ao longo dos séculos e as motivações disso. Para tanto, foi realizado o exame da bibliografia especializada procurando embasar a discussão acerca da temática de usos do passado.

Nesse trabalho, a discussão acerca dos acontecimentos europeus dos séculos XVIII e XIX são de suma importância, uma vez que, neste período, a consolidação dos Estados-nacionais enquanto entidade política passou a ser realidade. Partimos do pressuposto de que esta nova entidade não é natural (Hobsbawm: 1991: p. 30), pois o advento do nacionalismo fez aflorar uma necessidade de busca identitária para estreitar os laços de pertencimento entre pessoa, território e nação. Nesse sentido, a formação dos Estados-nação motivou a busca e utilização dos elementos do passado tanto a fim de legitimar as organizações presentes, quanto de forjar um passado grandioso que combinasse com as pretensões das potencias do período.

Procuramos problematizar as repercussões desse nacionalismo na forma com a qual a história dos povos autóctones da Britannia Romana foi utilizada nos estudos historiográficos como forma de legitimação. Por exemplo, os Galeses promoveram um regresso até a antiguidade, para tentar comprovar, a autenticidade de sua identidade. Isso é realizado, muitas vezes, sem a aplicação de métodos científicos e com a utili- 
zação e criação de narrativas que pretendem ser os mitos de origem de um povo grandioso. Ao pensar a utilização dos povos celtas nessa empreitada, o aspecto da escassez de fontes e a romantização de seus elementos ajudou a formatar uma imagem estereotipada que pouco condizia com esses povos mas dizia muito a respeito das pretensões políticas contemporâneas.

Com isso, nossa preocupação inicial foi analisar a representação da figura de Boudicea, líder dos Icenos que teve um importante papel de resistência à chegada romana. A partir disso, iniciamos a discussão a respeito de usos do passado, uma vez que essa líder foi uma importante figura para a criação da anglicidade. Tal discussão é pautada na identificação dos discursos construídos ao longo dos séculos para contar a história dessa mulher. Procuramos demonstrar que o modo como ela era apresentada mudava de acordo com a motivação política pela qual sua trajetória era revisitada. A seguir, abordamos a questão da religiosidade celta e as apropriações por qual ela passou no contexto do romantismo, situação que restringiu a pluralidade das relações e resultou na formação de um estereótipo irreal para esses povos.

\section{Usos do passado: A religiosidade Celta e seus desdobramentos na contemporaneidade}

A trajetória de Boudicea é representativa no que concerne à análise dos usos do passado. Para tratar desta figura feminina, recorremos a Richard Hingley, pois esse autor se dedica, dentre outros temas, ao estudo do contato entre populações nativas e o Império Romano. Com isso, 
e por meio de revisões teóricas e metodológicas, esse pesquisador questiona conceitos convencionais sobre o Império. Ao abordar Boudicea em "Concepções de Roma: uma perspectiva inglesa" Hingley (2005) comenta que a tragédia da bretã recebeu adaptações dramáticas de autores eduardianos e argumenta, também, que tais adaptações têm relação direta com os acontecimentos do Império Britânico. Quanto a isto, deve-se ponderar que as produções artísticas e culturais não estão isentas de discussões políticas de seu período. Os acontecimentos históricos e políticos de determinadas épocas tornam possíveis certas formas de pensamento que não teriam razão em outras. A expressão de tais formas de pensamento em produções culturais e artísticas ajuda a moldar o imaginário de uma época. Desse modo, as adaptações da Boudicea têm razão e motivação na contemporaneidade e, sendo assim, não está a parte das movimentações políticas do Império Britânico.

Em sequência, Hingley afirma que a representação de figuras históricas como Boudicea no contexto britânico vai do século XVI até o princípio do século XIX. Tal período coincide com a formação do Estado moderno inglês e, posteriormente, do Estado nacional, com pretensões imperialistas. Nesse contexto, para a autoafirmação da nação, era de suma importância a exaltação de modelos de heróis nacionais. O passado foi esquadrinhado como um catálogo de personagens relevantes que foram apropriados segundo a necessidade política contemporânea. Desse modo, a história serviu como agente legitimador do presente, por meio de uma construção política direcionada. 
Quando se trata dos povos celtas, todos esses assuntos são relacionados ainda a mais dois aspectos: a escassez de fontes e as apropriações que romantizam seus aspectos ao longo dos séculos e formaram um estereótipo muito pouco condizente com tais povos. As principais fontes textuais a respeito dos celtas foram escritas por autores gregos e romanos. A esse respeito, Le Roux e Guyonvarc'h (1999), pontuam que os gregos não se preocuparam em distinguir terminologias que estão relacionadas a denominações étnicas, pois essa é uma preocupação moderna. Porém, a maior inconveniência dos escritos antigos apontada pelos autores é a escassez de narrativas extensas, principalmente no que tange à religiosidade e, com isso, há muitas informações fragmentadas.

Esta fragmentação e escassez de documentação somada a romantização dos povos celtas ocasionou diversas apropriações da história e da religião desses povos. Durante a modernidade muitos sujeitos procuraram se atrelar aos celtas e aos druidas para construir um passado de glórias para suas nações. De acordo com Morgan:

Os celtas eram o reflexo das fantasias da época, e no País de Gales forneceram a uma nação oprimida e desesperadamente pequena, que pouco tinha de que se orgulhar na época, um passado magnífico, como consolo. (Morgan: 1997; p. 60)

Ainda, no que diz respeito a fontes para estudos da Antiguidade, deve-se analisar o papel da Arqueologia. As fontes arqueológicas muitas vezes apresentam panoramas mais amplos que os encontrados apenas nos textos e podem fornecer indícios de conflito e resistência, o que amplia e por vezes modifica as conclusões a respeito de um período. 
Contudo, a ciência arqueológica é recente e seu surgimento esteve muito atrelado ao interesse dos Estados, o que, por sua vez, gerou formas de apropriações semelhantes às comentadas acima. Pedro Paulo Funari (2010) comenta que os museus de artefatos, nesse contexto, "contribuíram para a formação de uma identidade nacional como, também, para reforçar a ideologia imperial das grandes potências" (FUNARI, 2010. P.86). Mais uma vez, pode-se perceber que as informações acadêmicas podem estar a serviço de interesses políticos, dependendo do posicionamento do historiador, do museólogo ou do arqueólogo. Portanto, dentro da análise dos usos do passado, percebemos que as fontes arqueológicas não estão isentas de passarem por ressignificações.

Retomando Hingley (2005; P.86) quanto à sua análise de Boudicea, podemos analisar a utilização da figura da mesma como símbolo, pois o autor comenta o levantamento de estátuas e a criação de espaços de memória para personagens históricas que foram consideradas heroicas em algum momento na história das atuais nações europeias. Devese, novamente, levar em consideração que as criação, organização e disposição destes espaços não se dão ao acaso, mas cumprem um propósito que pode enaltecer ou silenciar aspectos ou povos por completo. Portanto, tais espaços devem ser organizados, analisados e frequentados de forma crítica.

A esse respeito, Taís Pagoto Bélo (2014), desenvolve uma linha argumentativa que estabelece ligações entre a figura de Boudicea e outras mulheres de poder na Inglaterra, como as rainhas Vitória e Elizabeth I, bem como analisa as relações de nacionalismo atreladas à Boudi- 
cea. Quando utilizada nesse sentido, Boudicea representava símbolo de liderança feminina, portanto, esperava-se o legado criado para esta se estendesse às rainhas. Nesse esforço, foi erguida uma estátua em Londres em homenagem a personagem, em frente ao parlamento inglês. Com o apoio do Estado, Boudicea torna-se uma representação vitoriana.

Ao refletir sobre a estátua da guerreira em Cardiff, datada de 1916, a qual faz parte de um conjunto de estátuas de heróis escolhidos pelo povo galês localizada no saguão The Marble Hall, Bélo aponta a notável relação de Boudicea e o sentimento identitário em Gales. Tal saguão foi inaugurado pelo Secretário de Guerra, o que é, sem dúvida, um ato simbólico importante nessa relação. Embora a Boudicea de Cardiff possua diferenças de representação em relação à estátua de Londres, pois é a representação de uma mãe zelosa, em detrimento da imagem de uma guerreira poderosa, a autora aponta uma semelhança essencial: ambas representam ações femininas e estão localizadas em um espaço político de poder. Desse modo, a autora demonstra que Boudicea não foi uma figura estática no imaginário Inglês, passando por ressignificações ao longo dos séculos.

Assim como a figura de Boudicea foi apropriada de diferentes formas, a religiosidade celta também foi um elemento que passou por ressignificações. Isso se deu em consequência da romantização do século XIX, que contribuiu para apropriações. Nesse contexto, nossa pesquisa utilizará como exemplo as expressões religiosas dentro do druidismo, uma vez que esse fenômeno religioso foi muito utilizado para fins políticos, como veremos mais à frente. 
O termo druida é um conceito histórico e plural cuja acepção varia de acordo com a época. A história dos druidas é pouco conhecida devido à escassez de fontes, fato que dificulta as pesquisas, pois as lacunas documentais abrem uma possibilidade de variantes de interpretações sobre a religiosidade deste grupo, as quais, por sua vez, podem estar carregadas de ideologias e interesses políticos. Hoje se sabe que os druidas não utilizavam da escrita para suas narrativas, para esse povo da Antiguidade, a escrita era um meio sagrado de comunicação com os deuses, e eles a usavam como ritual religioso. O meio de conduzir o sagrado era através da oralidade, desta maneira os ensinamentos não foram transcritos para a literatura (FUNARI, 2009. P: 151).

Portanto, discutir o papel histórico desses personagens requer cuidado e atenção, tanto quando se parte da perspectiva teóricometodológica histórica, quanto quando se parte da perspectiva arqueológica, pois ambas já foram utilizadas para legitimar apropriações no mundo contemporâneo. Sendo assim, o estudo crítico desse período e desses povos passa obrigatoriamente pela revisão crítica da historiografia.

Muito se discutiu sobre os druidas e, embora alguns estudos tenham sido realizados, geralmente o que se sabe sobre eles provém de releituras de obras clássicas, pois há outro fator de complicação, que constitui a difícil interpretação dos materiais arqueológicos encontrados. De forma resumida, o que sabemos sobre eles são suas características intelectuais, pois compunham canções e poemas, eram intérpretes, adivinhos, professores, juristas, pedagogos, filósofos, intermediadores entre 
homens e deuses - uma espécie de sacerdotes intelectuais. É injusto restringir seu papel social a apenas uma autoridade religiosa. Esses homens pertenceram a uma casta étnica ou aristocrática que durante mais de mil anos e esteve atuando como guardiã de uma tradição oral preservada através dos séculos nas escolas druídicas. (FUNARI, 2009. P: 143).

Por muito tempo, gregos e romanos tentaram identificar esses povos misteriosos e, para isso, os classificaram com vários nomes: adivinhos, filósofos, bardos e magos. Desta forma, os druidas foram designados como portadores de uma filosofia oculta, mais tarde esta sabedoria chegou a ser comparada à dos brâmanes hindus e os magos persas, numa tentativa de justificar esses conhecimentos ocultos. Os druidas possuíam, portanto, grande conhecimento ao estilo pitagórico tanto da natureza como cosmologia.

As crenças druídicas eram, também, baseadas na imortalidade da alma e no seu renascimento, o mundo dos imortais era paralelo ao mundo visível e as almas dos parentes mortos ou dos guerreiros de batalha permeavam todo o espaço fatual (FUNARI, 2009. P: 137). Toda a recordação material era uma presença com um elo sagrado. Isso pode ser identificado no rito que mantinha a prática de guardar o crânio do familiar ou inimigo morto - ritual popular assimilado à igreja católica.

Em "As invenções das tradições" Morgan discorre sobre as transformações dos costumes no País de Gales a partir do século XVIII, segundo ele até os viajantes notaram as modificações promovidas naquela sociedade. 
Quase todos os costumes pitorescos do País de Gales tinham sido "completamente abandonados", sendo que não restava nenhum traço de certas crenças druídicas. (Morgan: 2014; p. 61)

$\mathrm{Na}$ verdade, tais modificações se deram devido à tentativa de buscar, no passado, algo com o que se pudesse legitimar a nação como grandiosa e soberana, que provocasse um sentimento de orgulho e pertencimento na população. Nesse contexto, Morgan buscou aproximações com os Druidas do mundo antigo, entretanto, os ritos e sacrifícios foram deixados de lado, pois não era interessante para uma nação já cristianizada evidenciar esse aspecto 'desprezível' da cultura ancestral.

Nesse período os patriotas e estudiosos galeses redescobriram velhas tradições históricas, linguísticas e literárias e criaram um passado que jamais existiu para substituir as tradições inadequadas. (Morgan: 2014; p. 62)

No século XVI semelhanças entre bardos e os druidas, começaram a ser procuradas. Nesse período, uma sequência de provérbios galeses chamados "Sabedoria dos antigos Druidas", no qual a ideia de que eles haviam construído monumentos misteriosos como o Stonehenge, difundiu-se grandemente. Neste caso a identidade religiosa desses povos era de bastante interesse, tanto que rituais e sacrifícios humanos foram atribuídos a eles por vários séculos. Já no século XVIII, as concepções sobre os druidas passaram por transformações: eles, que antes eram vistos como magos ou bruxos obscuros, passaram a ser associados aos 
galeses como figuras heróicas, como os primeiros defensores da nação (MORGAN, 2014. P.83).

Devido à euforia provocada pela curiosidade a respeito dos celtas, uma espécie de seita neodruídica surgiu, na qual um homem chamado Iolo Morganwg acreditava fielmente que era descendente e herdeiros dos druidas antigos. Desta forma o ressurgimento dos druidas foi, enfim, importante para a construção da identidade galesa. Esse resgate pelas "raízes" está fortemente relacionado com o surgimento dos nacionalismos do século XIX, evidenciando assim os usos políticos do passado. Cunliffe, B. defende que as ordens neodruidicas e religiões novas como a New Age e United Ancient Order of Female Druids pouco se relacionam com os druidas da antiguidade e medievo, e que, portanto, não se tratam de portadores de uma tradição ininterrupta ancestral, mas sim de uma releitura sobre este povo. (Vieira, Cunliffe, 2012. P. 120)

Existe, no imaginário da atualidade, uma visão estereotipada dos druidas, que consiste em um homem de barba longa e vestes brancas, que realiza sacrifícios humanos. Tal figura é muito comum na concepção coletiva, uma vez que está em convergência com as demandas da cultura pop do momento.

De certa forma, toda essa caracterização evidencia a forma de como eles são pensados ao longo dos tempos. Os celtas, assim como outros povos em situações similares, passaram por mudanças, sofreram com a cristianização e também foram utilizados para manipulação do passado a fim de legitimar o presente. Essa prática muito comum no século XVIII e XIX ainda permanece nos dias de hoje, uma vez que a 
maioria das ações políticas atuais está imbuída de manipulações e alterações na história.

Repensar o contexto histórico dos druidas na construção da nação galesa serve como um ponto de partida para entender o fenômeno da formação dos Estados nacionais modernos. Isso porque esses buscaram na antiguidade as raízes que julgaram melhores e mais adequadas para cumprir com o ideário nacionalista e demonstrar o quão grande e forte seriam as tradições nacionais. Para isso foram ocultadas partes de religiões de raízes ancestrais e rituais importantes para compreensão desta população.

\section{Considerações finais}

As perspectivas teóricas e metodológicas do estudo da Antiguidade passaram por muitas transformações desde o século XIX. Se, no contexto da formação dos Estados-nacionais, a história era instrumento da estruturação dos meios de legitimação dos poderes, atualmente tenta-se desvelar essas relações de poder que estavam imbricadas no discurso histórico. Desse modo, a reflexão sobre os usos do passado se faz extremamente necessária e, para isso, é preciso olhar novamente para as fontes e para a historiografia a respeito do mundo antigo sem perder de vista como as relações de poder do mundo contemporâneo tentam se utilizar delas.

No artigo, sinalizamos essas relações a partir de dois exemplos principais. O primeiro disse respeito à figura de Boadicea, que ocupou diferentes lugares no imaginário britânico: de guerreira que resiste ao 
Império Romano à símbolo representativo do poder de rainhas. O segundo exemplo se coloca a partir da relação galesa com a cultura céltica. Isso pois, a partir da Renascença Galesa, segundo o historiador Prys Morgan, diversos patriotas e estudiosos galeses redescobriram antigas tradições literárias, linguísticas e históricas e desenvolveram, por meio dessas, um passado que nunca existira de fato. Isso, pois, em 1700, os galeses já viviam conforme hábitos londrinos dos séculos passados que motivaram, então, tal redescoberta que visava uma substituição das tradições consideradas inadequadas.

A redescoberta druídica muito se atribui aos estudos de escritos como Guerra Gálicas de Julio Cesar e Agrícola de Tácito. Portanto, para conhecermos os druidas somos obrigados a interpretar os autores clássicos, gregos ou romanos (FUNARI, 2009. P: 138). Contudo, essas informações são rarefeitas e demonstram apenas a visão romana das situações. Foi como dito anteriormente, apenas a partir de 1700 que a figura do druida finalmente passou a ser relacionada aos galeses, sendo que no século XVIII a imagem druídica sofre alterações de forma expressiva. Foi nesse momento que os galeses passam, segundo Morgan, a respirar o druidismo, tornando o druída o principal defensor da nação galesa.

O País de Gales, afinal, não se enquadra como um Estado político ainda. Isso gerou no povo, principalmente no século XIX, o desejo de busca, através da invenção de tradições, de um passado satisfatório. Devido à decadência da história galesa, com a falta de tradição e passado heroico, a necessidade da reinvenção tornou-se necessária para que 
se pudesse cumprir os objetivos mencionados acima. $\mathrm{O}$ papel histórico dos druidas, enfim, exige sensibilidade e muita atenção no campo histórico e arqueológico como, também, segundo o historiador Pedro Vieira da Silva Peixoto, no campo social-contemporâneo. Os celtas e druidas permanecem, portanto, vivos para a cultura atual e, por meio de sua análise histórica, podemos trazer a reflexão a respeito das tradições e identidades antigas, facilmente inventadas e forjadas, em contextos de formação de identidade nacional e de legitimação do presente para fins políticos.

\section{Bibliografia}

BÉLO, T. P. Boudica e as facetas femininas ao longo do tempo: nacionalismo, feminismo, memória e poder, tese de doutorado, IFCHUnicamp.

FUNARI, Pedro. P. Celtas. DONNARD, Ana. As religiões que o mundo esqueceu. Contexto, 2009.

FUNARI, Pedro Paulo. Os historiadores e a cultura material. In: PINSLY, Carla Bassanezi (Org.). Fontes Históricas. 2.e.d., 2a reimpressão. São Paulo: Contexto, 2010.

MORGAN, P. "Da morte uma perspectiva: a busca do passado Galês no período romântico", in: A invenção das tradições. 9. ed. São Paulo: Paz e Terra, 2014.

LE ROUX, Françoise e GUYONVARC'H, Crhristian-J. A Civilização Celta. Mem Martins, 1999.

LUPI, João. Os Druidas. Revista Brathair, São Luís, v. 4, n.1, p. 70-79, 2004.

VIEIRA, Pedro. S.P. Os Druidas um passado presente. Revista Brathair, v. 12, n.2, p. 118-122, 2012. 
HOBSBAWM, Eric. Nações e Nacionalismos desde 1780. Trad. Antônio Candido. Rio de Janeiro, Paz e terra. 1991.

Recebido em: 18/05/2017

Aceito em: 10/05/2018 